\title{
Pablo González Casanova e a sociologia latino-americana
}

\author{
Edilmara Kayt Silveira Fernandes \\ Lia Pinheiro Barbosa
}

\begin{abstract}
RESUMO: Apesar de fortes influências externas, o desenvolvimento deumpensamento latino-americano autônomo tem crescentes expressões. Pablo González Casanova construiu uma escola de pensamento que conferiu à sociologia latino-americana um papel ético e político como ciência. Este artigo apresenta os principais conceitos, métodos, ideias e projetos que norteiam o pensamento do autor, com destaque para a sua contribuição intelectual na proposição de uma sociologia para a emancipação social.
\end{abstract}

PALAVRAS-CHAVE: Latino-Americana. crítico. Democracia. Colonialismo Interno.
Sociologia Pensamento

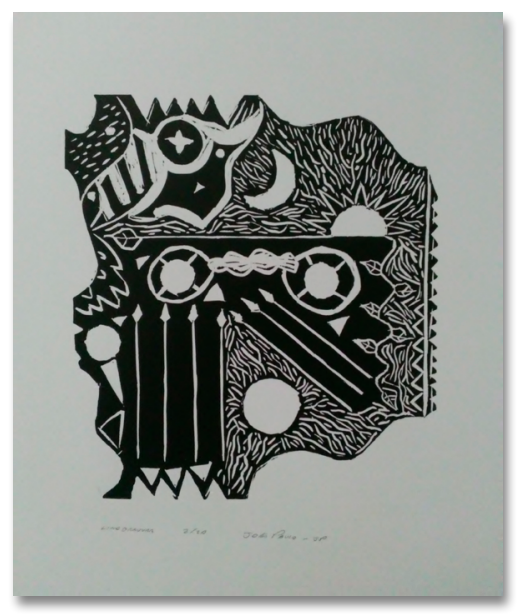

\section{Pablo González Casanova and latin american sociology}

Edilmara Kayt Silveira Fernandes

Mestra em Sociologia pelo Programa de PósGraduação em Sociologia da Universidade Estadual do Ceará (PPGS - UECE) e bacharela em Ciências Sociais pela Universidade Estadual Vale do Acaraú (UVA).

E-mail: edilmarakayt@yahoo.com.br

\section{Lia Pinheiro Barbosa}

Doutora em Estudos Latino-Americanos pela Universidad Nacional Autónoma de México (UNAM), com período sanduíche no Centro de Estudios Superiores de México y Centroamérica (CESMECA), e professora do Programa de Pós-Graduação em Sociologia (PPGS), do Mestrado Acadêmico Intercampi em Educação e Ensino (MAIE) e da Faculdade de Educação de Crateús (FAEC) da Universidade Estadual do Ceará (UECE).

E-mail: lia.barbosa@uece.br
ABSTRACT: In spite of strong external influences, there are powerful expressions of the development of an autonomous Latin American thought. Pablo González Casanova constructed a school of thought that gave Sociology Latin American ethical and political roles as a science. This article presents the main concepts, methods, ideals and projects that guide Casanova's thinking, with emphasis on his intellectual contributions in proposing a sociology for social emancipation.

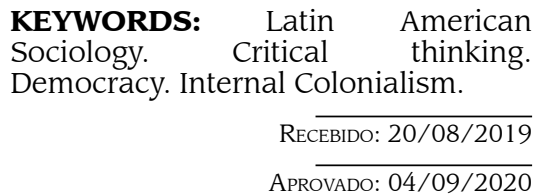




\section{Introdução}

O processo de desenvolvimento das ciências sociais é recente, se comparado à trajetória de outros campos do conhecimento, a exemplo da medicina, da matemática e da filosofia, para citar alguns. Na América Latina, embora tenhamos uma abordagem fundacional do pensamento social, inaugurado por Simón Rodríguez (1769 - 1854) e José Martí (1853 - 1895), defensores de um pensar nuestro americano, as bases do pensamento sociológico encontraram terreno fértil apenas ao longo do século XX. A formação da historiografia e, posteriormente, da sociologia na América Latina coincidiu com a consolidação da sociologia como ciência na Europa, de tal maneira que o método e as concepções das primeiras gerações formadas no século XIX e XX estão inspirados pelo seu nascedouro europeu, sobretudo pelas escolas francesa e alemã.

Logo após a I Guerra Mundial e a Revolução Soviética de 1917, aparecem as correntes de inspiração marxista e as primeiras aplicações historiográficas e sociológicas das categorias e do método do materialismo histórico-dialético, como chaves interpretativas da formação sociocultural, econômica e política da América Latina. Muitos pensadores latino-americanos desse período formaram-se como cientistas sociais em universidades europeias, trasladando conceitos, categorias de análise e abordagens metodológicas para interpretar a realidade sociocultural e político-econômica das nascentes repúblicas e do latente processo de desenvolvimento industrial capitalista na região.

Há aqueles que retornaram com o ímpeto de elaborar, a partir do diálogo com a sociologia europeia, um método sociológico próprio, de caráter latino-americanista, para interpretar os fenômenos sociais, a formação da nossa identidade como povo latino-americano e caribenho e suas interfaces na consolidação dos Estados nacionais, do desenvolvimento econômico, das matrizes culturais e da cultura política em nossa região. Sendo assim, apesar da forte influência externa, o desenvolvimento de uma ciência social autônoma que pense a América Latina por ela mesma tem expressões no continente e, em que pese a hegemonia epistemológica norte-americana e eurocentrada, há uma sociologia latino-americana própria em sua análise acerca da realidade 
sociocultural, das problemáticas inerentes a ela e da reescrita de sua própria história. Pablo González Casanova é uma das principais expressões do pensamento social latino-americano que, com métodos e conceitos próprios, construiu uma escola de pensamento que conferiu à sociologia um papel ético e político como ciência.

Levando isso em consideração, o objetivo do nosso artigo é apresentar os principais conceitos, métodos, ideias e projetos que norteiam o pensamento de Pablo González Casanova no desenvolvimento das ciências sociais latino-americanas, com destaque para sua contribuição intelectual na proposição de uma sociologia para a emancipação social. Para tanto, discorremos sobre a vida e obra de Pablo González Casanova, bem como a contextualização sócio-histórica da América Latina a partir das noções de marginalismo e desenvolvimento na perspectiva do autor. Os conceitos centrais que abordaremos na ótica do pensador mexicano são "exploração", "colonialismo interno" e "democracia". Ademais, acrescentamos uma seção que apresenta a perspectiva de González Casanova sobre o fazer nas ciências sociais neste novo século.

\section{Pablo González Casanova: vida e obra}

Pablo González Casanova nasceu em 1922, em Toluca, no México. Graduou-se em Direito pela Universidad Nacional Autónoma de México (UNAM), foi mestre em Ciências Históricas pelo Centro de Estudios Históricos do Colégio de México (COLMEX) e se tornou Doutor em Sociologia pela Université Paris-Sorbonne, em 1950. Em 1947, defendeu sua dissertação de mestrado, Misioneirismo y la modernidade Cristiana en el siglo XVIII, um estudo historiográfico acerca da forte tradição dos espanhóis na história das ideias no México, publicado em 1948 pela editora do Colégio de México (JACKSON; BLANCO, 2016). Em sua tese de doutorado, Introductión à la sociologie de la connaissance de l'Amérique espagnole à travers des donnés de l'historiografie, sob a orientação de Fernand Braudel, analisou as transformações nos diferentes enfoques utilizados pelos europeus, em diversas épocas, para pensarem a América, com destaque para as mudanças em suas próprias 
perspectivas de análise e de como aplicaram essas ideias à realidade americana (GANDARILLA SALGADO, 2006).

Ao retornar ao México, González Casanova se inseriu na vida intelectual, em um período histórico de consolidação de uma ciência social latino-americanista. A fundação da Comissão Econômica para a América Latina e o Caribe (CEPAL), em 1948, e a criação da Facultad Latinoamericana de Ciencias Sociales (FLACSO), em 1957, contribuíram à delimitação de chaves interpretativas para a abordagem da natureza do desenvolvimento social e político-econômico, em perspectiva latino-americana e caribenha. Em 1959, foi criada a primeira faculdade de sociologia da América Latina, na Universidad Nacional de Colombia, por Orlando Fals Borda e Camilo Torres, o primeiro impulsor da chamada sociologia sentipesante (FALS BORDA, 2009), em alusão ao princípio do pensar nuestro americano e ao reconhecimento da construção de um pensamento próprio a partir das idiossincrasias e particularidades das epistemologias e ontologias dos povos da América Latina e do Caribe.

Dessa maneira, na metade do século XX, se inaugura o debate em torno do desenvolvimento de uma teoria e de um método próprio ao campo da sociologia, isto é, de um pensar sociológico latino-americano. Nessa linha, outros centros de referência para o pensamento social latino-americano foram criados, como o Centro de Estudios Latinoamericanos (CELA), fundado em 1960 pela Facultad de Ciencias Políticas y Sociales da UNAM, e o Conselho Latino-Americano de Ciências Sociais (CLACSO), em 1967.

É nesse contexto de expansão das Ciências Sociais de corte latino-americanista que Pablo González Casanova inicia sua trajetória intelectual. Entre 1970 e 1972, foi reitor da UNAM, ocasião em que foram criados o Colégio de Ciências e Humanidades e o Sistema de Universidade Aberta da UNAM. Entre 1957 e 1965, foi diretor da Escola Nacional de Ciências Políticas e Sociais. Em duas ocasiões foi Presidente da Associação Latino-Americana de Sociologia (ALAS), entre os anos de 1969 e 1972 e os anos de 1983 e 1985, respectivamente. Pablo González Casanova foi presidente do Centro Latino-Americano de Pesquisas Sociais da UNESCO e do Comitê Diretivo da Faculdade Latino-Americana de Ciências Sociais (FLACSO). Recebeu diversos prêmios e reconhecimentos, com 
destaque para o Prêmio Nacional de Ciências e Artes em História, Ciências Sociais e Filosofia, em 1984; o Prêmio Universidade Nacional, em 1989, na categoria Pesquisa em Ciências Sociais. Em 2003, foi condecorado pela UNESCO com o Prêmio Internacional José Martí, concedido pelo seu compromisso intelectual com a defesa da identidade dos povos indígenas da América Latina. Em 2004, obteve a Ordem José Martí, concedida pelo governo de Cuba.

Em 2012, o COLMEX lhe outorgou o Prêmio Daniel Cosío Villegas, em reconhecimento aos seus aportes teórico-metodológicos às ciências sociais. Nesse mesmo ano, González Casanova recebeu o Prêmio Latino-Americano e Caribenho de Ciências Sociais, concedido pelo CLACSO. Ao receber esse prêmio, proferiu uma conferência centrada em três eixos: as ciências hegemônicas da globalização; o aprofundamento da crise e a dialética das necessidades imediatas; e as ciências sociais e o pensamento crítico alternativo e revolucionário na América Latina. Em 2018 foi nomeado Comandante Pablo Contreras pelo Comitê Clandestino Revolucionário Indígena da Comandância Geral do Exército Zapatista de Libertação Nacional (CCRI-CG-EZLN), um reconhecimento ao seu diálogo permanente com esse importante movimento indígena de Chiapas, México.

O sociólogo mexicano é autor, coautor e organizador de mais de 60 livros e 200 artigos e capítulos de livros. Recebeu doze títulos de doutor honoris causa e foi professor em reconhecidas universidades, como a Cambridge, a Oxford, a Computense de Madrid e a Escola Nacional de Ciências Políticas de Paris. É membro regular da Academia Mexicana de Pesquisa Científica e da American Association for the Advancement of Sciences, de Washington, Estados Unidos (GANDARILLA SALGADO, 2006).

O livro A democracia no México, publicado originalmente em 1965, solidifica a trajetória intelectual de Pablo González Casanova e é considerado um clássico das ciências sociais, pois inaugura linhas de investigação e reflexão que estabelecem o momento chave do desenvolvimento da sociologia no país. Importante referente intelectual e político, a obra analisa a dialética do poder, relacionando sua estrutura formal à estrutura real, sua dimensão nacional à internacional, com destaque para o desenvolvimento 
do conceito de "colonialismo interno", categoria de análise central para interpretar a estrutura social que emerge das relações coloniais e capitalistas e suas interfaces no âmbito das relações sociais. Apesar da estabilidade política e do crescimento econômico no contexto de publicação da obra, González Casanova (1969) apontou que o problema principal da nação era a ausência de democracia, do cumprimento das demandas de justiça social e de soberania. O mundo vivia a tensão da Guerra Fria, o Partido Revolucionário Institucional (PRI) dominava a arena política mexicana com relativa estabilidade desenvolvimentista e a América Latina era influenciada pela Revolução Cubana.

É fundamental salientarmos que, em meados da década de 1960, havia um importante debate teórico-político entre os mexicanos Pablo González Casanova e Rodolfo Stavenhagen, culminando no desenvolvimento da tese em torno do colonialismo interno, notadamente na publicação de obras de ambos os pensadores em 1965. ${ }^{1}$ Nesse período, estes pensadores articularam uma crítica contundente a uma série de lugares comuns do pensamento sociológico e econômico, associada à teoria da modernização. Para ambos, o conceito de colonialismo interno constituía a chave de consolidação do subdesenvolvimento latino-americano, sobretudo por expressar a reprodução da dialética colonial no interior das sociedades nacionais. Em outras palavras, seria um conceito revelador das lógicas de dominação centro-periferia que se manifestam em contextos locais, nacionais e regionais (SVAMPA, 2016).

Outras obras de relevo são Missionismo e modernidade no século XVIII no México (1948), Estudo da técnica social (1958), A literatura perseguida na crise da colônia (1958), Democracia no México (1965), As categorias do desenvolvimento econômico e a pesquisa em ciências sociais (1977), Sociologia da exploração (1969), A nova metafísica e o socialismo (1982), O estado dos partidos políticos no México (1983), Imperialismo e libertação na América Latina (1978), A hegemonia do povo e a luta centro-americana (1984), As novas ciências e as humanidades: da academia à política (2004).

1 Foi Rodolfo Stavenhagen (1981) quem desenvolveu o conceito de colonialismo interno. 
Assim, Pablo González Casanova consolidou uma abordagem teórico-metodológica caracterizada pela elaboração de conceitos próprios para a explicação da realidade em que estava inserido, utilizando ferramentas analíticas do empirismo, da historiografia, bem como procedimentos estatísticos e do materialismo histórico-dialético, atribuindo às ciências sociais no México maturidade intelectual. Ao assentar as bases de uma sociologia latino-americana, González Casanova inaugura o fim do monopólio dos estudos estrangeiros, a partir de uma perspectiva propriamente mexicana, porém articulada ao compromisso de fundar uma escola de pensamento destinada à análise do sistema político contemporâneo do país e da própria abordagem sociológica latino-americana.

No terreno político e ideológico, González Casanova carrega uma profunda relação com a universidade, o pluralismo ideológico e o socialismo. Por si mesmo, destaca que por "mis posiciones políticas personales decidí no meterme en ningún partido, y ser un intelectual orgánico de la universidad [...]. Defender e impulsar la universidad y las luchas por la democracia, la liberación y el socialismo en América Latina y el mundo" (GONZÁLEZ CASANOVA, 2015, p. 68). González Casanova manteve vínculo com os movimentos revolucionários e democráticos da Guatemala, Cuba, Chile, Nicarágua, El Salvador, México e Haiti, que influenciaram seu pensamento intelectual, orientado à análise da dialética da exploração, de processos democráticos e do pluralismo ideológico. González Casanova também manteve profundas relações de caráter intelectual e político com o mundo religioso católico-progressista, mantendo amizades com figuras importantes da Teologia da Libertação no México.

Nos diálogos estabelecidos com o EZLN, considera esse movimento indígena revolucionário como a resistência contemporânea mais avançada do mundo, sobretudo por exercer seu direito de autonomia e autodeterminação, a partir da construção de identidades culturais, políticas e jurídicas em seus territórios autônomos. Segundo Luís Hernández Navarro (2015), Pablo González Casanova tem como paixão a rebelião zapatista de Chiapas, a Revolução Cubana e a produção intelectual, investindo nelas seu capital político, seu pensamento crítico e sua vocação transformadora como um intelectual público. 
Para Roitman (2015), o pensamento de González Casanova passa por quatro etapas. A primeira, com a elaboração de sua tese de doutorado que aponta uma análise original ao que hoje se conhece como colonialidade do poder, ao revelar a ausência de um marco interpretativo próprio na América Hispânica dos séculos XVI a XVIII para interpretar sua realidade social. Pablo González Casanova argumentava que a América Hispânica assimilava enfoques e ideias da historiografia francesa e europeia para explicar sua própria realidade, conduzindo-a a uma alteração em torno à percepção de si mesma em função das ideologias, utopias e crenças culturais europeias. Em sua tese, González Casanova estabelece a relação entre sociologia e história, o estudo dos métodos de investigação, o papel político e ético do cientista social e as formas de interpretar a história colonial.

A segunda etapa do pensamento de González Casanova vai de 1950 a 1969 e é marcada pelo seu compromisso anticapitalista a partir do debate central da sociologia empírica e do uso dos métodos estatísticos aplicados à investigação social. Reivindica o conhecimento sociológico como instrumento para transformar a ordem social, promovendo um maior desenvolvimento político, econômico e social a partir do compromisso com a luta contra a exploração capitalista e a serviço da democracia. No processo do fazer sociológico, o pesquisador deve transparecer os significados trabalhados para impedir a corrupção dos conceitos e controlar o processo de investigação. Nessa fase, González Casanova constata a ausência de uma democracia real no México, de participação e de representação do povo na política, ao mesmo tempo em que inicia uma profícua crítica ao colonialismo interno. Nesse marco, aposta no socialismo como horizonte emancipatório, em um cenário político em que todos participem do desenvolvimento da nação, pois, para o autor, a exploração como fundamento da ordem capitalista seria incompatível com um sistema político democrático, em que se respeite a soberania dos povos da América Latina com a justa distribuição dos recursos (ROITMAN, 2015).

O terceiro momento de seu pensamento corresponde aos anos de 1969 a 1989 e é caracterizado pela reformulação das categorias "exploração", "democracia", "colonialismo interno" e 
"desenvolvimento". Nesse período, ele também se debruça sobre novas categorias, como "hegemonia do povo" e "soldado transnacional" e empreende estudos históricos sobre a dominação imperialista e a luta pela libertação nacional na América Latina, tecendo uma crítica ao socialismo burocrático a partir da análise dos fracassos da esquerda latino-americana. González Casanova faz uma defesa dos princípios do marxismo científico, questionando o uso de práticas autoritárias que não têm a ver com os valores da filosofia original do socialismo e convoca a esquerda latino-americana a refletir sobre a falta de capacidade crítica para superar as suas debilidades teóricas e práticas (ROITMAN, 2015).

A quarta etapa do pensamento de González Casanova vai de 1989 a 2008, período histórico caracterizado pela queda das torres gêmeas, nos Estados Unidos, e uma reconversão da ordem mundial, com a consolidação da hegemonia do imperialismo, dívida externa, dependência econômica junto ao Fundo Monetário Internacional e ao Banco Mundial e restauração do capitalismo nos antigos países socialistas (ROITMAN, 2015). Essa geopolítica econômica afetou diretamente os projetos de libertação nacional dos países do Sul, pois marcou o nascimento de um capitalismo totalitário e de exploração global que transformou a ordem mundial em um colonialismo global, ocasionando uma crise da democracia excludente. A insurgência armada zapatista, em 1994, é outro fenômeno político que marca o pensamento intelectual de González Casanova. Nesta etapa, repensa a definição de democracia, debruçando-se sobre os conceitos de "colonialismo global" e de "exploração global", bem como o projeto de uma democracia universal. Aponta para o problema do conhecimento das ciências da complexidade e tecnociências, interpretando-as como parte da luta política e teórica e compreendendo que o mundo é feito de muitos mundos, ${ }^{2}$ de modo que deveria existir uma alternativa democrática, socialista e libertadora frente ao neoliberalismo imperialista.

2 Pablo González Casanova incorpora a categoria "muitos mundos" do pensamento político zapatista. Uma das bandeiras de luta do EZLN era a demanda pelo reconhecimento, perante o Estado-nação, dos povos indígenas, de seu pensamento político e de sua forma de organização social em seus territórios. $\mathrm{Na}$ luta anticapitalista e anticolonial, os povos zapatistas reivindicam a possibilidade histórica de construção de "outros mundos possíveis", em que exerçam seu direito de autodeterminação em seus territórios em matéria de autonomia. 
Consideramos que há uma quinta etapa do pensamento sociológico de Pablo González Casanova, de 2007 até o presente. Nela, González Casanova argumenta em favor de uma ciência para a emancipação social e política da América Latina, exaltando a existência de uma ciência erigida pelos povos em contextos de luta e resistência política. Para González Casanova (2007), a ciência social crítica é a ciência das lutas para a ruptura com as forças opressoras e em prol da emancipação. Esse último período marca o aprofundamento de sua atuação como intelectual orgânico e militante, ao estreitar seus diálogos com o EZLN, o que culmina na assunção do cargo de comandante no CCRI-CG, em 2018.

\section{Marginalismo e desenvolvimento na América Latina}

Marginalismo, para González Casanova (2007; 2015), significa estar à margem do desenvolvimento do país, não participar do desenvolvimento econômico, social e cultural. Estão nessa condição de marginalismo aquelas populações que não têm nada, uma situação característica das sociedades subdesenvolvidas com desigual distribuição de riquezas, de cultura geral e técnica, e que possui dois ou mais conglomerados sócio-culturais, um super-participante e outro super-marginalizado, um dominante, o outro dominado.

Conforme Pablo González Casanova (2015), as sociedades latino-americanas são sociedades duais ou plurais, caracterizadas por uma heterogeneidade cultural, econômica e política que divide cada país em dois ou mais mundos com características distintas sob o domínio e a exploração de uns grupos culturais por outros. Nesse sentido:

[...] el "colonialismo" no es un fenómeno que sólo ocurra a escala internacional - como comúnmente se piensa -, sino que se da en el interior de una misma nación, en la medida en que hay en ella una heterogeneidad étnica, en que se ligan determinadas etnias con los grupos y clases dominantes, y otras con los dominados (GONZÁLEZ CASANOVA, 1975, p. 89). 
Conforme analisa González Casanova (1975), o marginalismo, a sociedade plural e o colonialismo interno são heranças do passado colonial que sobrevive no México e em outros países latino-americanos sob novas formas que caracterizam a sociedade e a política nacional. Para o caso mexicano, a sociedade marginal é predominantemente rural. A primeira dinâmica interna da desigualdade é a separação entre os mexicanos que participam do desenvolvimento e os que estão à margem do desenvolvimento.

Nessa divisão, o país se apresenta como um México ladino ${ }^{3}$ versus um México indígena. A população indígena encontra-se em uma posição social muito marginalizada e possui quase todos os atributos de uma sociedade colonial. González Casanova (1975) apresenta a questão indígena como um problema de colonialismo interno, fato que não está presente na consciência nacional, já que estamos "acostumbrados a pensar en el colonialismo como un fenómeno internacional, no hemos pensado en nuestro propio colonialismo" (GONZÁLEZ CASANOVA, 1975, p. 104). Nas colônias há racismo, discriminação, exploração de tipo colonial, formas ditatoriais, alinhamento simbólico-ideológico de uma população dominada com outra raça e cultura diferente. Contudo, há uma diferença com o colonialismo internacional: os indígenas podem escapar física e culturalmente das colônias internas por meio da mobilidade social e espacial, embora seja um processo de poucos indivíduos e que não reduz significativamente o colonialismo interno.

O autor aponta para duas formas de colonialismo interno: no primeiro, a "metrópole" exerce monopólio sobre o comércio e o crédito indígena, promovendo relações de intercâmbio desfavoráveis para os indígenas em uma descapitalização permanente. Nesse contexto, as comunidades sobrevivem da monocultura e têm dependência da economia. A segunda forma de colonialismo interno apresenta-se como uma exploração conjunta da população indígena por distintas classes sociais da população ladina. A exploração é combinada em uma mescla de feudalismo, capitalismo, escravismo, trabalho assalariado e forçado, parceria, peonagem e serviços gratuitos. Há ainda a privação às populações indígenas do

3 Ladino diz respeito ao mestiço. 
acesso às suas terras, além da exploração dos artesanatos e das discriminações sociais, linguísticas, das formas de vestir, jurídicas, políticas e sindicais (GONZÁLEZ CASANOVA, 1975).

Em uma sociedade plural, o marginalismo social e cultural se relaciona com o marginalismo político, influencia e é influenciado por ele. Conforme argumenta González Casanova (1975, p. 108), "Muchos habitantes son marginales a la política, no tienen política, son objetos políticos, parte de la política de los que sí la tienen. no son sujetos políticos en la información, ni en la conciencia, ni en la organización, ni en la acción". A democratização é vista pelo autor como o requisito indispensável ao desenvolvimento e cabe às classes governantes a percepção desse papel atribuído à democracia. As regiões com cultura tradicionalista e população marginal, sem direitos, liberdade ou organização política, exigem esforços para a democratização e a garantia de representação política aos grupos marginalizados, sobretudo as populações indígenas, além de tarefas legislativas, políticas e econômicas que assegurem o ingresso dessa população à vida cívica, à uma cidadania econômica e política plena.

\section{A dialética da exploração}

Em ensaio escrito no $150^{\circ}$ aniversário de Karl Marx, Pablo González Casanova (1969) aprofunda o método do materialismo histórico-dialético para a análise da dialética da exploração no marco do desenvolvimento e da expansão do capitalismo na América Latina. É um ensaio que evoca o rigor metodológico vinculado à pesquisa militante ao que o pensador denomina como ensaio-resposta à interpretação crítica das estruturas da exploração nas sociedades latino-americanas. Na introdução à leitura, ele afirma:

El libro está escrito sobre todo para los estudiantes de América Latina y de aquellos países que han adoptado el falso rigor empirista, tan estrechamente asociado a las ciencias sociales predominantes hoy en Estados Unidos. También está escrito para quienes se quedan en los slogans y las palabras pomposas del marxismo ortodoxo y dogmático, renunciando a las grandes tradiciones que el propio marxismo tiene de investigación científica de alto nivel, 
que siempre ha complementado y acompañado a la investigación militante (GONZÁLEZ CASANOVA, 1969, p. 03).

Para González Casanova (1969), portanto, a desigualdade ajuda a ocultar a exploração ao aparecer como fenômeno natural, social, cultural e religioso que legitima o mundo existente. Já a exploração não se pode justificar da mesma forma e lhe é dada uma atenção secundária, uma vez que muitos falam de desigualdade e poucos são os que falam em exploração, pois definir a exploração implica reconhecer sua existência como uma relação social predominante e de características globais.

O autor analisa que, no processo de mundialização e evolução da economia-mundo capitalista, houve o predomínio de organizações que se articularam em estruturas de caráter mundial ou global, afetando a vida do conjunto da espécie humana e da natureza. González Casanova (2015, p. 158) acredita que "analizar el problema de la explotación de unos hombres por otros a escala global tiene hoy un significado nuevo: no sólo permitirá plantear y eventualmente resolver el problema de los explotados, sino el de los seres humanos". De modo semelhante, é impossível pensar na história passada da humanidade sem as relações de exploração ou pensar em uma política de liberdade, igualdade e fraternidade, em uma política de democracia, sem uma política contra a exploração. Nesse sentido, o autor trata a exploração como categoria essencial para a compreensão e construção das mediações do capitalismo à luz do materialismo histórico-dialético.

Para González Casanova (2015), a exploração é parte da história humana e começou de forma regular e periódica com a agricultura, a partir de explorações tributárias, escravistas, feudais, assalariadas que se combinam com os modos de produção, sistemas de colonização e com as estruturas das empresas produtoras e colonizadoras. Mesmo as sucessivas reformas do capitalismo provocaram efeitos macroeconômicos e globais, alterando os termos originais da exploração, mas não puseram fim a ela. O pensador argumenta que "De los 'pobres' y 'extremadamente pobres', excluidos y desposeídos, surge hasta nuestros días una enorme población que 'se ofrece a trabajar como sea y en lo que 
sea', en condiciones óptimas para sus empleadores" (GONZÁLEZ CASANOVA, 2015, p. 167).

Neste contexto, Pablo González Casanova (2015) aponta para um projeto de democracia sem excluídos, que assuma "a la libertad de los proyectos democráticos anteriores, la igualdad de los socialistas y marxistas, la liberación de los leninistas y castristas, la fraternidad de los cristianos primitivos y otros fundadores de las grandes religiones, y la dignidad de los mayas mexicanos" (GONZÁLEZ CASANOVA, 2015, p. 179).

Em meio a crises de proporções mundiais, surgem novos movimentos de luta na América Latina contra o fascismo da dependência, o neoliberalismo, o militarismo e a burocracia autoritária. Em suma, para o autor:

[...] [la] lucha por la democracia, con poder del pueblo, parece seguir siendo en última instancia una lucha por el socialismo democrático, y la lucha por la "democracia limitada" [...] sigue siendo, en última instancia, una lucha por el imperio de las transnacionales y la reproducción ampliada y conquistadora del capital que hoy domina a escala mundial (GONZÁLEZ CASANOVA, 2015, p. 191).

No contexto da América Latina, a luta pela democracia está ligada às lutas pela independência, pela justiça social, bem como pela disputa hegemônica do Estado em uma perspectiva popular. Nesse debate, na história recente, começou-se a falar de "pós-capitalismo", "pós-imperialismo" e "pós-colonialismo". Para González Casanova (2015), esses novos termos deram a impressão de que o mal do capitalismo, do imperialismo e do colonialismo tinham sido superados pela história. Entretanto, ocultam as suas novas formas de opressão e injustiça. Nas últimas décadas do século XX, os novos movimentos sociais latino-americanos experimentaram:

[...] la alegría efimera de las democracias que sustituyeron a los dictadores militares, en pocos años descubrieron que sus sucesores neoliberales imponían la dictadura de las políticas del Banco Mundial y del Fondo Monetario internacional, y una democracia de las minorías, con las minorías y para las minorías. Los nuevos movimientos de la periferia y del centro del 
mundo experimentaron en su vida cotidiana las nuevas formas de opresión e injusticia del colonialismo, el imperialismo y el capitalismo (GONZÁLEZ CASANOVA, 2015, p. 322).

\section{0 colonialismo interno na dialética da exploração}

Para explicar o conceito de colonialismo interno, González Casanova (1969) indica, inicialmente, que as fronteiras políticas influenciam na formulação e no uso das categorias sociológicas. Estas surgem e são aplicadas em relação aos problemas internos de uma nação ou território, enquanto outras são pensadas para problemáticas internacionais, sem que necessariamente se tenha precisão até que ponto umas e outras sejam intercambiáveis. Ele atenta que é fundamental compreender "hasta qué punto las categorías que generalmente se usan para explicar los problemas internos sirven para explicar los problemas internacionales y viceversa" (GONZÁLEZ CASANOVA, 1969, p. 223).

O autor aponta que, geralmente, a ideia de civilização indica uma análise internacional ou universal da história; a noção de uma sociedade dual ou plural indica a análise interna de nações ou territórios subdesenvolvidos; os conceitos de classe e de estrato social se dão a partir do estudo interno das sociedades sem se ligarem às relações de classe e estratificação das nações; e o conceito de colonialismo assinala todo um fenômeno internacional entre povos e nações distintas. Nesse contexto de conceitos incompletos, Pablo González Casanova (1969) indica o caráter intercambiável da noção de colonialismo e de estrutura colonial, compreendo-os também como fenômeno interno às nações colonizadas. Assim:

El objetivo de ese trabajo es precisar el carácter relativamente intercambiable de la noción de colonialismo y de estructura colonial, haciendo hincapié en el colonialismo como un fenómeno interno. Se busca con ello destacar, en el interior de las fronteras políticas, un fenómeno que no sólo es internacional sino intranacional, y cuyo valor explicativo para los problemas de desarrollo quizá resulte cada vez más importante desde el punto de vista interno de las nuevas naciones [...] donde existe una sociedad plural (GONZÁLEZ CASANOVA, 1969, p. 223 - 224). 
Para González Casanova (1969), o colonialismo interno reflete estruturas de poder herdeiras das relações coloniais e que se reproduziram, historicamente, no processo de constituição dos Estados nacionais e nos regimes políticos da América Latina. O conceito expressa as relações sociais de dominação e exploração entre grupos culturais heterogêneos e cujas diferenças podem se manifestar nas relações estabelecidas entre campo e cidade, entre classes sociais ou mesmo nas concepções civilizatórias. Para o autor, o colonialismo interno surgiu junto ao movimento de independência das antigas colônias. A partir da independência política, surge um neocolonialismo no qual desaparece o domínio de "nativos" por estrangeiros e aparece a noção de domínio e exploração de "nativos" por "nativos", a opressão de umas comunidades por outras, a dominação que uns povos exercem sobre outros. As novas nações conservaram o caráter dual e as relações similares às da sociedade colonial.

Ao analisar a questão indígena, González Casanova (1969) demonstra como se expressa o colonialismo interno nas relações de dominação e exploração das comunidades indígenas nas colônias mexicanas. Essa estrutura colonial e o colonialismo interno diferem da estrutura de classes, pois há uma relação de dominação e exploração de uma população (que possui distintas classes, proprietários e trabalhadores) por outra população com distintas classes (proprietários e trabalhadores). Desse modo, o colonialismo interno é uma estrutura de relações sociais de domínio e exploração entre grupos culturais heterogêneos.

O desenvolvimento internacional ocorre dentro de uma estrutura colonial e seus motores não são apenas econômicos, mas também militares, políticos, culturais e espirituais. A função econômica e comercial de uma colônia é imediata e geral, mas o monopólio se estende ao terreno da cultura e da informação. A política colonialista reforça o monopólio econômico e cultural mediante o domínio militar, político e administrativo. A estrutura colonial nas sociedades contemporâneas está ligada ao desenvolvimento (técnico, institucional, cultural) desigual e a formas de exploração combinadas com o modelo clássico de desenvolvimento. 
O fim do colonialismo, portanto, não representou o fim dos problemas surgidos com o controle estrangeiro e as definições de colonialismo não são suficientes para explicá-los. Por isso, o autor propõe o conceito de "colonialismo interno" para explicar as características das sociedades plurais da América Latina. Para o autor:

Olvidarla con el argumento de que el colonialismo pertenece al pasado, o es exclusivamente un fenómeno internacional, o de que el capitalismo y la lucha de clases por sí solos explican los problemas de la sociedad y el estado, es clausurar la comprensión de la esencia de los problemas de la democracia y la liberación latinoamericana (GONZÁLEZ CASANOVA, 2015, p. 307).

Pablo González Casanova (2015) crítica os marxistas ortodoxos por passarem por cima do papel do colonialismo interno na acumulação do capital e na dominação dos povos e utilizar as "categorías de 'Clases' tales como 'semifeudalismo' o 'semicapitalismo' sin analizar sus patrones coloniales, periféricos" (GONZÁLEZ CASANOVA, 2015, p. 294). No contexto analítico da América Latina, as categorias externas se transformaram em categorias internas. Muitos grupos sociais intermediários expressam uma mudança significativa nas relações coloniais puras, representam uma mudança no colonialismo, mas o colonialismo ainda está ali. Esses grupos são parte das estruturas do neocolonialismo, representadas pelos novos empresários, trabalhadores qualificados e pequena burguesia. No contexto do colonialismo interno, a classe dominante colonial pode trilhar dois caminhos:

[...] puede caer bajo la hegemonía del capital transnacional, o quedar sujeta a los distintos regímenes militares y políticos: de hecho domina y gobierna, a través de coaliciones interclase, mediante la represión y el consenso, la explotación y la negociación neocoloniales (GONZÁLEZ CASANOVA, 2015, p. 296).

González Casanova (2015) ressalta que as possibilidades de mobilidade social lançam expectativas na população mais pobre das sociedades coloniais, que passam a acreditar em melhorias das condições de vida alcançáveis por meio da educação ou da migração. Essas posibilidades: 
[...] verdaderas o ficticias de una sociedad-en-que-se-puede-mejorar son exaltadas por los sectores medios, especialmente por los que trabajan para la educación, la administración y el Gobierno. Los sectores medios en estas sociedades desempeñan varios papeles que reproducen y remodelan las desigualdades coloniales (GONZÁLEZ CASANOVA, 2015, p. 297).

As nacionalidades e igualdades formais acabam por ocultar a situação colonial interna. Os estratos sociais e a mobilidade social suprimem da consciência coletiva o perfil das desigualdades crescentes. Assim, ele aponta ainda que:

[...] el colonialismo, el imperialismo y la globalización, en sus variadas formas, son las últimas fuentes de la sociedad dependiente internacional y transnacional, las comunidades indias y las poblaciones indias son la principal expresión de la sociedad colonial y neocolonial internacional (GONZÁLEZ CASANOVA, 2015, p. 302).

\section{0 conceito de democracia}

As categorias que apresentamos até aqui foram desenvolvidas por Pablo González Casanova a par de outra preocupação central em sua trajetória intelectual, qual seja, o de pensar a natureza dos processos democráticos no México e em perspectiva latino-americana. Segundo González Casanova (1975), a democracia é um termo ambíguo. Os centros de hegemonia imperialista caracterizados por repressão e autoritarismo falam de democracia e as forças populares e revolucionárias têm distintos conceitos de democracia, que vão desde sua relação com o socialismo a uma democracia como projeto burguês.

Há várias correntes ou formações da luta pela democracia: há os que lutam pela democracia como cidadãos para manter ou recuperar os regimes constitucionais, os direitos, os sistemas de partidos políticos, o sufrágio em ditaduras; há os trabalhadores e as populações exploradas e excluídas que lutam articuladamente pela democracia sindical, na defesa de salários, na prestação de serviços etc.; e há os que lutam combinando as duas grandes correntes 
anteriores: a frente democrática e a frente do trabalho. Estes planejam a luta pela independência nacional, pelo território e por um povo soberano. Esta luta é manifestada, sobretudo, pela terra, pela cultura e pelo idioma. É uma luta contra a exploração interna e externa, nacional e transnacional e pela distribuição do excedente.

O projeto democrático das classes dominantes também possui uma grande variedade de definições com relação aos problemas sociais e nacionais. Consiste em um projeto de democracia limitada, sem justiça social, sem libertação nacional, ao mesmo tempo em que difunde uma ideia de que o problema social é um problema individual a partir do paradigma da eficácia humana:

[...] el nuevo proyecto conservador llega a plantear un sistema democrático en que no haya derecho a escoger una política económica distinta de la neoliberal, ni un gobierno democrático con fuerte apoyo popular. Propone una democracia "gobernable" en que las elecciones se limiten a elegir a los grupos de las clases dominantes (o cooptadas por ellas) que muestren tener mayor apoyo en las urnas semivacías. Propone una democracia sin opciones en la que vote la minoría de los ciudadanos para escoger entre un pequeño grupo de políticos profesionales cuyas diferencias ideológicas y programáticas son insignificantes (GONZÁLEZ CASANOVA, 2015, p. 203).

González Casanova (2015) é enfático ao afirmar que a democracia de fato é uma utopia, pois as ditas democracias já existentes têm sido todas excludentes, construídas a partir de uma noção oligárquica e elitista existente no subconsciente. O autor supõe pensar a democracia por meio da luta por sua conquista e pela sua construção a partir do poder emanado do povo, isto é, em uma perspectiva popular. Nesse sentido, seu projeto de democracia se configura pela hegemonia popular, em que as forças sociais exploradas e dominadas participam amplamente em todos os âmbitos de decisões públicas.

A alternativa à democracia das classes dominantes é, para González Casanova (2015), a organização da luta democrática de bases populares e de pretensões universais. Em suas palavras: " $L a$ polis de la democracia emergente abarca a los marginados y excluidos, así como una política de solidaridad mundial; no puede limitarse 
al país legal ni al territorio nacional, aunque éstos sean su punto de partida" (GONZÁLEZ CASANOVA, 2015, p. 207).

Para o autor, a luta popular pela democracia sem justiça social e sem independência nacional não faz sentido. No contexto da América Latina, as forças democráticas do povo enfrentam um inimigo comum: os círculos mais reacionários do imperialismo norte-americano e das burguesias latino-americanas.

Há na perspectiva de González Casanova (2015) uma relação mútua entre democracia e socialismo, enfatizando que o socialismo realmente existente não é o socialismo e que a democracia realmente existente não é a democracia. Ele acredita que "sin democracia no habrá socialismo, y sin socialismo no habrá democracia" (GONZÁlEZ CASANOVA, 2015, p. 333). A proposta de democracia e socialismo do autor envolve:

[... a la democracia como método de gobierno y al socialismo como método de producción por una sociedad civil que no esté dominada por los monopolios privados y por un estado que no sea el instrumento de éstos o de los burócratas (...) Para tener éxito requiere una solidaridad mundial, que es también incipiente (GONZÁLEZ CASANOVA, 2015, p. 210).

Para González Casanova (2015), uma luta pelo socialismo tem necessariamente que envolver uma luta pela democracia ou não poderá ter êxito. Em suas palavras:

O la lucha por el socialismo se ve como lucha por la democracia y también por la liberación, o la concepción de la misma será muy pobre. Y esa lucha por el socialismo, la liberación y la democracia tiene que estudiarse más allá del eurocentrismo clásico o del aldeanismo tercermundista, como proyecto realmente mundial, lo que exige el esfuerzo de entenderlo desde el Sur y de rechazar cualquier idea implícita de una democracia colonial o de un socialismo con colonias, es decir de rechazar el tipo de ideas que muchas veces no explicitó el pensamiento socialdemócrata, socialista y comunista (GONZÁLEZ CASANOVA, 2015, p. 237).

O autor enfatiza que pelo legado do século XIX não é possível uma luta mundial pelo socialismo sem uma luta também contra 
o colonialismo e o imperialismo. E, pelo legado das experiências do século XX, não é possível a luta pelo socialismo sem que ela seja mundial e também pela democracia (GONZÁLEZ CASANOVA, 2015). Nesse marco, ele vê a luta pela democracia articulada à disputa hegemônica no âmbito do poder e da política, pela libertação e pelo socialismo como a livre autodeterminação dos povos, como a única alternativa para a sobrevivência mundial.

Nesse sentido, haveria uma confrontação entre dois sentidos de socialismo: um como projeto histórico e outro como processo histórico e uma luta pela democracia que se projeta contra a democracia que se alcançou. Esta se fez para assegurar que o país fosse governado por proprietários, burocratas e políticos que definiram o conceito de democracia para aplicar à política das elites e das classes dominantes (GONZÁLEZ CASANOVA, 2015).

González Casanova (2015) afirma que a democracia é uma utopia, no sentido em que todas as democracias existentes têm sido excludentes. Sendo assim, uma democracia enquanto governo do povo, para o povo e pelo povo, é ainda uma utopia para todo o povo e o desafio é realizá-la. Entretanto, para o autor, uma democracia inclusiva não é apenas uma utopia, mas um caminho para que se cumpra as utopias que ainda não se cumpriram:

[...] la explicación general del fracaso de las utopías democráticas es que para alcanzar sus objetivos, sus defensores fueron incapaces de construir una democracia no excluyente (...) ni siquiera se plantearon el problema en el terreno teórico, menos en el práctico (GONZÁLEZ CASANOVA, 2015, p. 212).

Com base no exposto, Pablo González Casanova (2015) destaca que o conceito de democracia predominante na América Latina é de caráter oligárquico e elitista, em que a participação popular se limita aos interesses de uma democracia restrita à representação e à tomada de decisões do projeto liberal. Ele ainda analisa o sistema de acumulação capitalista como principal obstáculo à democracia. Para o autor, o planejamento de uma democracia universal não excludente é o problema central das ciências sociais, que teriam de estudar os variados caminhos, práticas e opções das redes estruturantes e suas organizações, bem como preparar os 
povos para pensar e atuar com pensamento crítico em uma investigação dialogal entre as ciências e os movimentos sociais para construir uma utopia realizável.

\section{As Ciências Sociais no século XXI}

Com ampla trajetória intelectual e na própria construção das ciências sociais na América Latina, Pablo González Casanova (2015) dedica tempo a uma autoanálise enquanto cientista social. Em sua concepção, no contexto do século XXI, para se fazer ciências sociais é necessário desvendar os conceitos para nós mesmos e para os outros, redefinir nossas próprias palavras e fazermos uma autocrítica, pois ainda somos leigos de uma ação coletiva e é necessário estabelecer pontes e políticas entre quem faz a análise social e quem as amplia e as põe em prática.

Para ele, ao fazermos ciências sociais, necessitamos procurar que nossas palavras conduzam a uma ação coletiva ou a várias, ao mesmo tempo em que deve primar pelo fim de uma cultura sem diálogo entre os que são predominantemente reflexivos e os que são predominantemente ativistas. Os cientistas sociais precisam aprender a pensar e atuar ao lado dos movimentos populares, pois os conhecimentos não são exclusivos dos investigadores especializados. Na academia, devemos cultivar precisão e compreensão com a arte da coerência entre o que se diz e o que se faz.

Em sua perspectiva, precisamos reavaliar os conceitos fundamentais que utilizamos em sete pontos específicos (cf. GONZÁLEZ CASANOVA, 2015):

$\left.1^{\circ}\right)$ Não podemos ficar restritos ao conceito de modos de produção e avançarmos em nossa reflexão sociológica em termos de uma unidade completa de modos de produção e de dominação, usar outras categorias, corrigir a tendência ao economicismo.

$\left.2^{\circ}\right)$ Não podemos ficar no conceito de sistema capitalista ou ordem mundial capitalista, já que se trata de um sistema de muitos sistemas e subsistemas e de uma ordem em que as organizações desempenham um papel protagonista sem precedentes na história. Nesse sentido, devemos integrar as novas ciências e tecnociências ao pensamento crítico e alternativo. 
$\left.3^{\circ}\right)$ Também não podemos ficar no conceito tradicional de luta de classes que conserva um sentido fabril e economicista e o conceito de exploração não é suficientemente compreensivo. Esses conceitos requerem ser complementados ou superados pelos conceitos de dominação e apropriação do excedente e da riqueza à custa dos trabalhadores e dos povos. Ambos os conceitos vinculam o poder político, repressivo, informático, cultural e social com as relações de produção.

$\left.4^{\circ}\right)$ Não podemos ficar no conceito de imperialismo, pois em cada Estado-nação se dão vínculos com outros Estados-nação, com o capital multinacional e transnacional, com o Estado global e com seus associados locais. Se falamos de imperialismo, devemos compreender que este também se encontra em casa; se falamos de dependência, não concluamos que não vale à pena lutar pelos interesses nacionais e se falamos de colonialismo, este não obedece a fronteiras nacionais, atravessa em formas internacionais, transnacionais e intranacional. Nesse sentido, o autor chama a atenção para a necessidade de vincular o local ao nacional e ao internacional.

$\left.5^{\circ}\right)$ Não podemos ficar no conceito de desenvolvimento desigual. Este tem características sociais, culturais, políticas e econômicas. As categorias de centro e periferia do mundo têm de ser adicionadas às de centro e de periferia em cada país e região. Os fenômenos globais (colonialismo, neocolonialismo, pós-colonialismo) têm de ser associados com os fenômenos internos.

$\left.6^{\circ}\right)$ Os conceitos usados para os países periféricos (marginalização dos benefícios do desenvolvimento, dualidade da sociedade, cultura, política, econômica, exclusão, sociedade formal e informal) também se aplicam ao centro do mundo e aos países metropolitanos e centrais.

$\left.7^{\circ}\right)$ É necessário que os cientistas sociais se aprofundem também nos conceitos utilizados pelos movimentos populares. Conceitos como os de movimento social, sociedade civil, democracia com poder do povo e pluralismo, conceitos de moral, de gênero, de direito às diferenças culturais e às inclinações sexuais são fundamentais para complementar o pensamento crítico. 
Com base no exposto, podemos inferir que, em seus 98 anos de idade, Pablo González Casanova consolidou uma importante contribuição às ciências sociais e, em particular, à sociologia latino-americana, sobretudo ao atribuir-lhe, conjuntamente ao seu método teórico-analítico, o atributo de uma sociologia para a emancipação social. A vasta produção teórica de González Casanova demonstra seu compromisso ético em analisar com afinco categorias centrais à compreensão do processo de formação sócio-histórica e política da América Latina, no sentido de compreender, em chave sociológica, fenômenos como o do colonialismo interno e dos sistemas democráticos frágeis, entretanto dando um passo à frente, ao defender que a ciência social e os que dela fazem seu ofício devem primar por construir uma ciência para a emancipação humana.

\section{Considerações finais}

Pablo González Casanova figura entre os intelectuais precursores da própria escola de pensamento sociológico latino-americano, tornando-se reconhecido internacionalmente por seus aportes teórico-metodológicos a uma sociologia latino-americana e com compromisso ético-político com a transformação da realidade social. Para Roitman (2015), González Casanova assume uma vocação humanista e o compromisso ético-político com seu tempo e sua realidade social, ao apresentar uma proposta democrática aberta à crítica e ao debate, compreendendo a ciência comprometida com os valores da liberdade, democracia e socialismo, pela construção de um mundo alternativo ao neoliberalismo como necessidade histórica.

Sua obra é multidisciplinar, pois vai da sociologia à ciência política, economia, história, antropologia, ciências da vida, da matéria, ou, o que chamava de ciências da complexidade. Os temas de sua obra perpassam as relações sociais de exploração, estruturas do colonialismo interno, luta por democracia e desenvolvimento, sempre com o horizonte emancipatório como bússola para pensar uma sociologia com compromisso social. 
Em González Casanova, ética política e crítica teórica são inseparáveis. O autor, de forma coerente, aproxima sua fala ao seu fazer científico e seu agir no mundo. É comprometido não apenas com o desenvolvimento das ciências sociais de forma autônoma, criativa e original, como também se compromete em pensar e propor alternativas para um mundo melhor com justiça social e liberdade. Os conceitos, ideias e projetos que elabora não se limitam ao caso mexicano, nem ao período das publicações, mas atravessam as fronteiras geográficas e históricas e contribuem para pensarmos os problemas não superados da América Latina e o próprio fazer científico das ciências sociais e os desafios deste século.

Por tal razão, Pablo González Casanova é um clássico das ciências sociais latino-americanas, um intelectual imprescindível à história das ciências humanas e sociais na América Latina, que deve ser lido, relido e revisitado em sua perspectiva teórica e militante.

\section{REFERÊNCIAS}

FALS BORDA, O. Una sociologia sentipensante para América Latina. Buenos Aires: CLACSO, 2009.

GANDARILLA SALGADO, J. G. Pablo González Casanova. In: MARTINS, C. E.; SADER, E.; JINKINGS, I. Latinoamericana: enciclopédia contemporânea da América Latina e do Caribe. São Paulo: Boitempo, 2006. [s.p.]. Disponível em: http://latinoamericana.wiki.br/verbetes/g/ gonzalez-casanova-pablo. Acesso em: 07 mar. 2019.

GONZÁLEZ CASANOVA, P. De la sociología del poder a la sociología de la explotación: pensar América Latina en el siglo XXI. Presentación de Marcos Roitman Rosenmann. Ciudad de México; Buenos Aires: Siglo XXI; CLACSO, 2015.

El saber y el conocer de los pueblos: primer coloquio internacional in memoriam Andrés Aubry. Chiapas: Universidad de la Tierra, 2007.

La democracia en México. Ciudad de México: Era, 1975.

Sociología de la explotación. Ciudad de México: Siglo XXI, 1969. 
HERNÁNDEZ NAVARRO, L. A Don Pablo. In: GONZÁLEZ CASANOVA, $P$. De la sociología del poder a la sociología de la explotación: pensar América Latina en el siglo XXI. Presentación de Marcos Roitman Rosenmann. Ciudad de México; Buenos Aires: Siglo XXI; CLACSO, 2015. p. $441-460$.

JACKSON, L. C.; BLANCO, A. O caudilho da sociologia mexicana: Pablo González Casanova e a democracia no México. Tempo Social, São Paulo, v. 28, n. 3, p. $117-143,2016$.

ROITMAN, Marcos. Pablo González Casanova: de la sociología del poder a la sociología de la explotación. In: GONZÁLEZ CASANOVA, P. De la sociología del poder a la sociología de la explotación: pensar América Latina en el siglo XXI. Presentación de Marcos Roitman Rosenmann. Ciudad de México; Buenos Aires: Siglo XXI; CLACSO, 2015. p. 09 - 54.

STAVENHAGEN, R. Siete tesis equivocadas sobre América Latina, 1965. In: Sociología y Subdesarrollo. Ciudad de México: Nuestro Tiempo, 1981. p. $15-84$.

SVAMPA, M. Debates latinoamericanos: indianismo, desarrollo, dependência, populismo. Buenos Aires: Edhasa, 2016. 